\title{
MODIFICAÇÃO DE CRENÇAS E MODELAÇÃO PROATIVA DE METAS: PERSPECTIVAS DE INTERFACE ${ }^{1}$
}

Andréia da Silva Bez

\begin{abstract}
RESUMO
Neste artigo, avalia-se o potencial descritivo e explanatório da Teoria de Conciliação de Metas de Rauen (2013) em intervenções de Terapia Cognitiva. Argumenta-se que o sucesso da intervenção consiste na projeção colaborativa de metas, e a terapia consiste na elaboração de hipóteses abdutivas antefactuais, cuja execução pode, na medida em que gera resultados conciliáveis com as metas traçadas, enfraquecer ou flexibilizar a conexão categórica de causa e efeito em crenças disfuncionais.
\end{abstract}

Palavras-chave: Teoria de Conciliação de Metas. Terapia Cognitiva. Modelação Proativa de Metas. Hipóteses Abdutivas Antefactuais. Crenças Disfuncionais.

\section{INTRODUÇÃO}

A Terapia Cognitiva (TC) é uma abordagem psicológica baseada em evidências, que se caracteriza como uma forma focalizada de psicoterapia de curto prazo com orientação de metas para a solução de problemas e a prevenção de recaídas. A TC visa a questionar processos cognitivos disfuncionais para modificar emoções e comportamentos, pois é um modelo de compreensão do indivíduo, assente na interação de pensamentos, sentimentos e comportamentos.

A interação paciente/terapeuta é complexa. Entre outras razões, isso se deve ao fato de que o terapeuta, de um lado, tem objetivos específicos e um conjunto de conhecimentos teóricos próprios, e o paciente, de outro, encontra-se orientado pelo seu sistema de crenças e pensamentos automáticos. Inferências ocorrem tanto como um aspecto intrínseco do processo comunicacional entre esses atores, como um aspecto essencial da busca dos sentidos dos pensamentos e crenças disfuncionais e, consequentemente, da compreensão do esquema cognitivo do 
indivíduo. Além disso, e fundamentalmente, processos inferenciais complexos estão envolvidos na proposição de metas que são necessárias para o prosseguimento do processo terapêutico (WAINER et al., 2005).

Dada a importância dos processos inferenciais, argumenta-se neste estudo que é de extrema importância para o desenvolvimento da TC a aproximação e/ou interface com teorias mais abrangentes sobre o tema (psicologia evolutiva, ciências cognitivas, neurociências, entre outras). Entre as possibilidades de interface, destaca-se a proposta abdutivo/dedutiva de modelação proativa de metas de Rauen (2013). Rauen propõe um modelo de quatro estágios para descrever e explicar como os indivíduos modelam metas, partindo da emergência de uma meta [1], passando pela formulação de uma hipótese abdutiva de solução [2], pela execução da ação [3] e pela avaliação dedutiva da consecução dessa ação [4]. O modelo de Rauen consiste numa ampliação da Teoria da Relevância (TR) de Sperber e Wilson (2001) ao considerar o raciocínio abdutivo na formulação de uma hipótese antefactual para a modelação de metas, revendo o caráter essencialmente reativo da teoria, e ao incorporar o módulo dedutivo da TR como parte do mecanismo de checagem dessa hipótese abdutiva.

De acordo com Rauen (2013, p. 190), tome-se o exemplo de um indivíduo i que imagina estar em um estado de meta $Q$ no futuro. Considere-se que, diante dessa emergência, ele elabora uma hipótese abdutiva de que há uma conexão nomológica entre $P$ e $Q$, tal que $P$ é concebido como uma ação antecedente minimamente suficiente para atingir um estado consequente $Q$, aqui representando a dita meta $Q$. Segue-se da abdução a provável execução da ação $P$ na expectativa de se atingir $Q$, sob o escopo dedutivo da hipótese abdutiva, de maneira que, seja executando ou não executando a ação antecedente $P$, as consequências serão dedutivamente avaliadas a partir da hipótese abdutiva funcionando como premissa maior.

Diante dessa breve contextualização, este ensaio é uma primeira tentativa em esboçar as possibilidades de interface entre essas áreas no que concerne à avaliação de metas e à confirmação de hipóteses e, consequentemente, à flexibilização e à modificação de crenças em virtude da ampliação do ambiente cognitivo, bem como, do enfraquecimento das hipóteses categóricas.

Para tanto, essa reflexão está organizada em cinco seções: na primeira apresentam-se os principais fundamentos da terapia cognitiva, na segunda, a teoria da modelação proativa de metas, na terceira, a aplicação da proposta teórica de 
Rauen (2013), na quarta, a flexibilização e a modificação de crenças na TC, e, na seção final, as considerações sobre possibilidades de interface entre TC e este modelo.

\section{TERAPIA COGNITIVA: FUNDAMENTOS E PRINCÍPIOS}

A terapia cognitiva tem sua origem na tentativa de Aaron Beck explicar os processos psicológicos da depressão com base na teoria psicanalítica freudiana. Como suas pesquisas e observações clínicas não provaram o modelo das motivações inconscientes da psicanálise e ignoravam os fatores cognitivos encontrados, Beck acabou por estruturar um modelo cognitivo para a depressão, hoje, estendido a várias outras sintomatologias psicológicas. Desde então, as psicoterapias baseadas neste modelo progrediram consideravelmente aplicando-se a diferentes transtornos psicológicos.

No que diz respeito ao processamento da informação, a TC assevera que a maneira como as pessoas percebem e processam a realidade influencia a maneira como elas se sentem e se comportam. A TC postula haver pensamentos automáticos nas fronteiras da consciência. Esses pensamentos ocorrem espontânea e rapidamente e constituem uma interpretação imediata de qualquer situação. Eles podem ser descritos em termos de palavras (Não vou, pois serei humilhado) ou imagens (Não vou ao casamento porque me enxerguei derrubando as bandejas).

Em geral, as pessoas não estão imediatamente conscientes dos pensamentos automáticos, de modo que eles são aceitos como plausíveis e sua avaliação como verdadeira (KNAPP; BECK, 2008). Além disso, eles são específicos a uma situação e desencadeiam reações emocionais, comportamentais e fisiológicas.

Essas interpretações da realidade se fundamentam em estruturas cognitivas denominadas esquemas. Os esquemas compõem-se de crenças centrais ou nucleares, de crenças intermediárias ou subjacentes e de pensamentos automáticos. Os pensamentos automáticos estão em um nível mais superficial e acessível; as crenças intermediárias ou subjacentes estão em um segundo nível; e as crenças centrais ou nucleares estão em um nível mais profundo. Em função dessa superficialidade, segundo Dattilio (2006), os esquemas dos indivíduos são geralmente revelados através de seus pensamentos automáticos. 
As crenças intermediárias, por sua vez, são responsáveis pelos pensamentos automáticos. Elas estão mais enraizadas do que os pensamentos automáticos e visam a dar sentido ao ambiente. As crenças intermediárias configuram um caminho para acessar o modelo cognitivo da pessoa, pois elas orientam as ações e posturas cotidianas do indivíduo. São elas que operacionalizam as crenças centrais e apresentam-se como regras, atitudes ou suposições na forma de estruturas enunciativas do tipo "Se... então..." ou "deveria" (Se sou incapaz, então não vou dar conta desse trabalho). Segundo Neufeld e Cavenage (2010), elas podem ser chamadas também de pressupostos subjacentes ou condicionais ou ainda de crenças associadas, formando um conjunto geralmente coerente que serve de apoio às crenças centrais com as quais apresentam relação.

As crenças centrais, finalmente, são rígidas, profundas e fundamentais. Elas configuram-se como verdade absoluta, imutável, global e generalizada. O desenvolvimento das crenças centrais ocorre desde o início da vida. Elas consistem no acúmulo de experiências e aprendizagens obtidas das interações do indivíduo com outras pessoas significativas e da vivência de muitas situações que fortaleçam essa ideia. Elas representam a essência dos mecanismos desenvolvidos pelas pessoas para lidar com as situações cotidianas e, quando disfuncionais, são o foco da intervenção. De acordo com Beck (1997), as crenças centrais podem ser relacionadas ao próprio indivíduo, às outras pessoas ou ao mundo, ou seja, à maneira como os indivíduos percebem a si mesmos, os outros, o mundo e também o futuro. A intervenção do terapeuta consiste em torná-las mais realistas ou flexíveis.

Outro aspecto que deve ser observado com atenção pelo terapeuta consiste na prospecção de estratégias que a pessoa está utilizando para manter protegido o seu sistema de crenças, um dos entraves encontrados para a evolução do tratamento. Para Neufeld e Cavenage (2010), esses comportamentos consistem em estratégias compensatórias que causam sofrimento quando são executadas em excesso. As estratégias compensatórias atuam como uma forma de retroalimentar o sistema de crenças. Quando as crenças são disfuncionais, acabam por reforçar e auxiliar a manutenção dos sintomas e do sofrimento (toma-se como exemplo, a inatividade de um deprimido: Se eu nada faço, não destruo a crença de incapacidade).

A formulação do tratamento fundamenta-se na conceituação cognitiva do caso, que consiste em elaborar um modelo, ou seja, uma representação de como a pessoa está funcionando e de como a terapia vai atuar. Na conceituação cognitiva, 
paciente e terapeuta preenchem em conjunto um diagrama desse esquema cognitivo, buscando os significados dos pensamentos e das crenças, bem como se há estratégias compensatórias para mantê-lo. Eles, então, estabelecem juntos as prioridades e o plano a ser seguido, lançando hipóteses diagnósticas e um prognóstico do tratamento. Esse enfoque colaborativo e participativo entre terapeuta e paciente sugere uma proposta de adesão do paciente à terapia, pois se observa nesta etapa um aumento da motivação e da compreensão de todo o processo, convergindo para a mudança.

Em síntese, a abordagem psicológica da TC prioriza a compreensão da cognição, de maneira a possibilitar ao individuo o seu bem estar. Nessa abordagem, o processo inferencial é tomado como um aspecto primordial para o estabelecimento desses sentidos, a compreensão dos esquemas cognitivos e a construção de um plano de tratamento que se fundamenta em metas a serem atingidas a curto, médio e longo prazo. Segue-se disso a importância fundamental de se considerar um modelo de modelação proativa de metas tal como a abordagem abdutivo/dedutiva proposta por Rauen (2013).

\section{AS METAS E A FORMULAÇÃO DE HIPÓTESES ABDUTIVAS ANTEFACTUAIS}

A modelação de hipóteses abdutivas antefactuais desenvolvida por Rauen (2013) conecta, do ponto de vista simbólico, a noção de relevância com a noção de meta. Rauen fundamenta sua abordagem na Teoria da Relevância (TR) de Sperber e Wilson (1986, 1995), assumindo o princípio cognitivo de que a cognição é guiada para maximizar a relevância, e o princípio comunicativo de que 0 ato de comunicação gera expectativas de relevância; e na proposta de Lindsay e Gorayska (2004), para quem relevância é um predicado dependente de meta, pois os indivíduos atribuem relevância a inputs que se conectam com um propósito.

Segundo Rauen (2013), a modelação proativa de metas consiste num processo cognitivo de quatro estágios: formulação de meta, formulação de uma hipótese abdutiva antefactual, execução e checagem. O primeiro estágio consiste na formulação de uma meta. Nesse estágio, assume-se que um indivíduo i formula uma meta $Q$ no tempo $t_{1}$. O segundo estágio consiste na formulação de pelo menos uma hipótese abdutiva antefactual para atingir a meta $Q$. De acordo com o autor, nesse processo, o individuo $i$ acessa um conjunto de múltiplas suposições factuais de sua 
memória enciclopédica (seu corpus de crença), de modo a identificar pelo menos uma ação antecedente $P$ admitida como minimamente suficiente para atingir 0 estado consequente $Q$. O terceiro estágio consiste na provável execução da ação antecedente $P$. O quarto estágio consiste na checagem dedutiva da formulação hipotética. Nos termos de Rauen (2013, p. 9), a checagem dedutiva "[...] consiste na avaliação da (in)ação antecedente $P$ no escopo dedutivo da formulação hipotética 'Se $P$, então $Q$ '”.

No estágio de checagem, o autor apresenta os conceitos de conciliação de metas e o de confirmação de hipóteses. Na conciliação de metas, observa-se se o resultado da ação $P$ é semelhante à meta imaginada pelo indivíduo $i$. $\mathrm{Na}$ confirmação da hipótese abdutiva antefactual, observa-se se o resultado da ação $P$ corrobora a hipótese abdutiva antefactual de que a ação $P$ causa o efeito $Q$.

O processo de checagem gera quatro tipos de consecução: conciliação ativa, inconciliação ativa, conciliação passiva e inconciliação passiva. Numa conciliação ativa, atinge-se a meta e confirma-se a hipótese abdutiva antefactual. Essa hipótese é fortalecida e estocada na memória enciclopédica como uma suposição factual a ser mobilizada em situações futuras. Numa inconciliação ativa, rejeita-se a hipótese, pelo menos na situação ad hoc, e a inconciliação passa a ser relevante quando põe o indivíduo no dilema entre desistir ou perseverar na consecução da meta. Rauen (2013, p. 11) observa que nessas situações o indivíduo sopesa a força da meta e da consecução, prevalecendo a mais forte. Se a inconciliação prevalecer, o indivíduo desiste da meta. Se a meta prevalecer, o indivíduo abduz uma nova hipótese de solução. Numa conciliação passiva, a hipótese fica suspensa e a consecução repentina da meta pode gerar a mesma consequência da conciliação ativa ou pode ganhar relevância justamente em função de a meta ter sido atingida apesar da inação. Numa inconciliação passiva, confirma-se a hipótese e ela é fortalecida e estocada na memória. Todavia, pode-se seguir o dilema da inconciliação ativa, quando a inação havia sido involuntária, ou demandas psicológicas, quando a inação decorre de hesitações, medos, entre outras razões.

Rauen, por fim, sustenta que o processo de checagem leva a modelar uma gradação de força de enunciados "Se P, então Q", tratados por ele como "enunciados hipotéticos". Para o autor, 
se bicondicional $(P \leftrightarrow Q)$, admitindo-se inconciliações passivas. Quando $P$ é apenas suficiente, a formulação torna-se condicional $(P \rightarrow Q)$, admitindo-se conciliações passivas. Quando $P$ é necessário, mas não garante $Q$, a formulação torna-se habilitadora $(P \leftarrow Q)$, admitindo-se inconciliações ativas. Por fim, quando todas as possibilidades são plausíveis a formulação tornase tautológica ( $P-Q)$. (RAUEN, 2013, p. 14).

Conhecida a abordagem abdutivo/dedutiva de Rauen em linhas gerais, apresenta-se na seguinte seção uma ilustração de como é possível modelar metas terapêuticas proativamente.

\section{ILUSTRANDO A MODELAÇÃO PROATIVA DE METAS}

Conforme Rauen (2013) propõe, a modelação de hipóteses abdutivas antefactuais deriva da formulação de uma meta. Tome-se o exemplo hipotético de Ana, uma jovem mulher com situação econômica que atende somente suas necessidades básicas e que necessita desenvolver atividades físicas regulares a fim de obter bom condicionamento cardiovascular. Do processo terapêutico, decorre a proposição negociada da seguinte meta:

[1] Ana $i$ formula a meta $Q$ de obter bom condicionamento cardiovascular em $t_{1}$.

Sendo $t_{1}$ o tempo da formulação da meta, obter bom condicionamento cardiovascular a expressão da meta $Q$ ainda não executada em $t_{1}$, o output da consecução desse estágio pode ser assim representado:

obter condicionamento cardiovascular, Ana

No segundo estágio, Ana $i$ seleciona pelo menos uma hipótese abdutiva antefactual $H_{a}$ para atingir a meta $Q$.

[2] Ana $i$ abduz uma hipótese antefactual $H_{a}$ para atingir a meta $Q$ de obter bom condicionamento cardiovascular em $t_{2}$.

Essa formulação, ainda incompleta, capta a ideia de que é preciso, num tempo $t_{2}$ que sucede $t_{1}$, conectar uma ação antecedente $P$, admitida por Ana $i$ como pelo menos suficiente para atingir a meta $Q$. Obviamente, a memória enciclopédica de Ana $i$ deve conter um conjunto extenso de ações antecedentes $P$ capaz de compor uma hipótese abdutiva antefactual $H_{a}$. A título de exemplo, tome-se o caso de a sua memória ter selecionado apenas o conjunto $S_{1-3}$ abaixo: 
$S_{1}$ - Fazer caminhadas

$S_{2}$ - Frequentar uma academia

$S_{3}$ - Contratar personal trainer

Rauen (2013) sugere que a escolha da melhor hipótese $H_{a}$ está atrelada ao atendimento de alguns critérios. Diante da situação econômica de Ana e tomando-se apenas o conjunto de suposições $S_{1-3}$, a suposição factual $S_{1}$ de que "Fazer caminhadas" seria a melhor solução, pois $S_{1}$ deixa-se mapear numa formulação hipotética do tipo "Se $P$, então Q", uma vez que "se Ana fizer caminhadas $P$, então ela obterá bom condicionamento cardiovascular Q"; $S_{1}$ é uma ação plausível de ser considerada por Ana como pelo menos suficiente para obter bom condicionamento cardiovascular; $S_{1}$ converte-se numa hipótese que, dentre o conjunto restrito $S_{1-3}$ de suposições, é aquela de mais baixo custo de processamento diante do efeito fixo de obter bom condicionamento cardiovascular e, $S_{1}$ converte-se numa hipótese que atende o critério de melhor solução, pois é uma atividade que ela pode executar sozinha, estabelecendo horários e frequência próprios e, principalmente, não implica investimentos financeiros, como no caso da academia e do personal trainer.

A busca de soluções para um objetivo a ser atingido na terapia converge com essas ideias, pois são consideradas soluções eficazes (leia-se relevantes) aquelas que conseguem atingir seus objetivos e, ao mesmo tempo, maximizam consequências positivas (os benefícios) e minimizam consequências negativas (os custos) (NEZU; NEZU, 2002).

O output do segundo estágio é a hipótese abdutiva antefactual $H_{a}$ a seguir:

[2b] Se Ana $i$ fizer caminhadas $P$, então Ana obterá bom condicionamento cardiovascular $Q$.

O output de [2b] também pode ser assim representado:

[1] Q obter condicionamento cardiovascular, Ana

[2] P Q caminhar, Ana obter condicionamento cardiovascular, Ana

O terceiro estágio da modelação abdutivo/dedutiva de Rauen (2013) consiste na provável execução da ação antecedente $P$ :

[3a] Ana $i$ faz caminhadas $P$ para obter bom condicionamento cardiovascular $Q$ num tempo $t_{3}$, ou

[3b] Ana $i$ não faz caminhadas $P$ para obter bom condicionamento cardiovascular $Q$ num tempo $t_{3}$

A execução é o momento em que Ana faz ou não a caminhada para obter bom condicionamento cardiovascular. Rauen (2013) defende a hipótese de que o modelo 
agentivo da execução de $P$ emerge em primeiro plano: Ana faz caminhadas para obter bom condicionamento cardiovascular. Todavia, pode ser o caso de Ana não ter condições de executar a ação $P$, seja porque questões alheias à sua decisão a impedem (mudanças de horário no trabalho, condições meteorológicas, etc.), seja porque ela falha em executá-la, pondo em suspeição a própria meta e/ou sua execução. Nesse último caso, Ana, embora formule a meta de obter bom condicionamento cardiovascular e a hipótese pertinente de fazer caminhadas, mesmo tendo condições, não o faz.

A versão positiva do output do terceiro estágio pode ser vista a seguir:

\begin{tabular}{llll}
{$[1]$} & & $\mathrm{Q}$ & \\
{$[2]$} & $\mathrm{P}$ & $\mathrm{Q}$ & $\begin{array}{l}\text { caminhar, Ana obter condicionamento cardiovascular, Ana } \\
\text { [3] }\end{array}$ \\
$\mathrm{P}$ & \multicolumn{3}{c}{ caminhar, Ana }
\end{tabular}

O quarto estágio consiste na checagem dedutiva da formulação hipotética:

[4a] Considerando-se [2] "Se $P$, então $Q$ " e [3a] $P$, a Ana $i$ atinge a meta de obter bom condicionamento cardiovascular $Q$ ' num tempo $t_{4}$, ou

[4b] Considerando-se [2] "Se $P$, então $Q$ " e [3b] $\neg P$, a Ana $i$ não atinge a meta de obter bom condicionamento cardiovascular $\neg Q$ ' num tempo $t_{4}$

Nesse estágio, Ana avalia os resultados de sua ação ou inação. Na versão [4a], ela observa os resultados objetivos da caminhada. Na versão [4b], de forma constrangedora em algum grau, Ana observa não atingir a meta.

A versão positiva do output do quarto estágio pode ser vista a seguir:

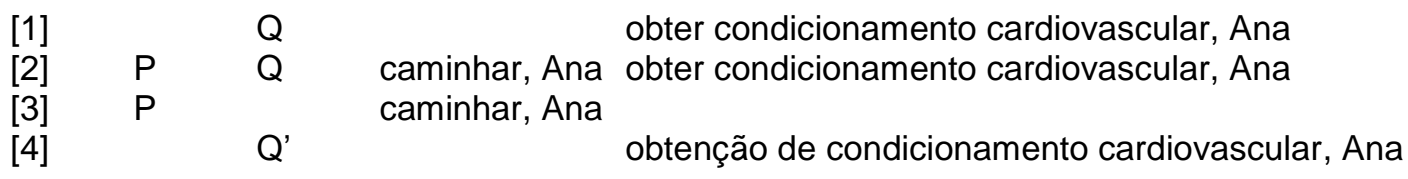

Decorre do output do quarto estágio a conciliação de metas e a confirmação de hipóteses. Na conciliação ativa, Ana faz a caminhada e obtém bom condicionamento cardiovascular; na inconciliação ativa, Ana faz a caminhada, mas não obtém bom condicionamento cardiovascular (o joelho incomoda, a caminhada faz calos nos pés); na conciliação passiva, Ana não faz a caminhada, mas obtém bom condicionamento cardiovascular por outras estratégias (é oferecida ginástica laboral no seu emprego, ela passa a dançar regularmente, etc.); e na inconciliação passiva, Ana não faz caminhada, e não obtém bom condicionamento cardiovascular.

No que se refere aos efeitos cognitivos: na conciliação ativa, Ana atinge a meta $Q$ e confirma a hipótese $H_{a}$, que é fortalecida e estocada como um esquema de 
crenças na memória enciclopédica; na inconciliação ativa, a hipótese $H_{a}$ é rejeitada, embora a relevância consista em pôr Ana no dilema entre desistir ou perseverar na consecução da meta; na conciliação passiva, a hipótese $H_{a}$ fica suspensa, e pode chegar à mesma consequência da conciliação ativa ou pode ganhar relevância por a meta ter sido atingida apesar da inação de Ana; e na inconciliação passiva [5d], às avessas, a hipótese $H_{a}$ é também confirmada, mesmo que Ana não tenha executado a ação antecedente $P$. Aqui, a questão terapêutica que ganha destaque é identificar se a inação é involuntária ou não.

Por fim, segue-se dessas consecuções a avaliação da força da conexão entre a ação antecedente $P$ e o estado consequente $Q$. Por hipótese, a hipótese abdutiva emergiu na terapia como categórica $(P \Leftrightarrow Q)$ e modelaria somente o sucesso, ou seja, conciliações ativas: Ana iria caminhar e iria obter bom condicionamento cardiovascular. Ocorrendo problemas ou dilemas, essa formulação revelou-se bicondicional $(P \leftrightarrow Q)$, admitindo-se inconciliações passivas: Os horários de Ana mudaram e ela não pôde caminhar, ou ela encontrou subterfúgios para evitar as caminhadas. Quando, por exemplo, outras atividades geraram o resultado esperado, a caminhada $P$ se revelou apenas suficiente, e a conexão tornou-se condicional $(P \rightarrow Q)$, admitindo-se conciliações passivas. Quando a caminhada $P$ revelou-se necessária, mas não garantiu a consecução da meta $Q$, a formulação tornou-se habilitadora $(Q \rightarrow P)$, admitindo-se inconciliações ativas. Por fim, quando todas as possibilidades se revelaram plausíveis, a formulação tornou-se tautológica $(P-Q)$.

Essas modulações de força da conexão entre ações, decorrentes da avaliação da conciliação de metas e da confirmação de hipóteses, pode lançar luzes sobre a flexibilização e a modificação de crenças dos pacientes. Precisamente este é o objeto da seção a seguir.

\section{FLEXIBILIZAÇÃO E MODIFICAÇÃO DE CRENÇAS NA TC}

Conforme Rangé (2001, p. 6), os esquemas cognitivos são comparados às "fórmulas" que uma pessoa tem a seu dispor para lidar com as situações, de maneira a evitar todo o complexo processamento que existe quando uma situação é nova. Os esquemas "orientam e ajudam uma pessoa a selecionar os detalhes 
relevantes do ambiente e a evocar dados armazenados na memória também relevantes para a sua interpretação".

O terapeuta, de posse do modelo cognitivo do seu paciente e de metas para solução dos problemas, deve utilizar-se de técnicas que mobilizem suposições que minimizem custos de processamento e maximizem ganhos cognitivos para 0 paciente. Para a reestruturação de uma crença, como prevê a TR, supõe-se que efeitos cognitivos sejam da ordem do fortalecimento de uma suposição, da contradição ou eliminação, ou ainda da combinação de uma suposição memorizada com uma nova, gerando novas implicações. A técnica de identificação e de monitoramento dos pensamentos automáticos consiste em um desses meios. Através do registro dos pensamentos disfuncionais, o paciente identifica a situação, a intensidade da emoção e o pensamento automático desencadeador. Após a identificação desses aspectos, terapeuta e paciente buscam evidências favoráveis e não favoráveis a esse pensamento, levando o paciente a questioná-los.

Todavia, para que as mudanças estruturais ocorram de fato, além de modificar pensamentos automáticos, deve-se analisar e corrigir essas crenças. As crenças são avaliadas da mesma forma que os pensamentos automáticos, com a procura de evidências que as sustente, com um acréscimo que é o teste de realidade.

De acordo com Rauen (2013), a conciliação de metas e a confirmação de hipóteses possibilita uma explicação para os graus de confiança que os indivíduos conferem às hipóteses abdutivas antefactuais tomadas como a melhor solução para chegar à meta. Isso converge com a flexibilização e/ou a modificação de crenças no esquema cognitivo de um paciente.

Retomando o exemplo de Ana, no estágio [2], a hipótese $H_{a}$ é categórica $(P \Leftrightarrow Q)$, pois ao formular a hipótese de fazer caminhadas na expectativa de obter bom condicionamento cardiovascular, Ana acredita que a ação antecedente é suficiente, necessária e certa. Essa ação deixa de ser certa diante de problemas ou dilemas $(P \leftrightarrow Q)$, deixa de ser necessária, quando outras atividades redundam na mesma conclusão $(P \rightarrow Q)$, pode ser necessária, mas não suficiente, no caso da dor no joelho $(Q \rightarrow P)$, ou mesmo pode ser totalmente flexibilizada, quando qualquer relação pode ser estabelecida $(P-Q)$.

De acordo com Leahy (2007), em casos de pessoas que sofrem com a preocupação excessiva, existe um sentimento de culpa e de fracasso pessoal 
quando não conseguem atingir alguma meta, pois acreditam que a solução encontrada era essencial e a única maneira para atingi-la. Diante deste resultado, chega-se ao impasse: desistir da meta ou persistir. Ao desistir são mobilizados pensamentos e crenças que confirmam esse sentimento de fracasso e incapacidade.

Quando o paciente encontra dificuldades (obstáculos, medos, hesitações) em executar, pode ser utilizada a técnica imagística de ensaio cognitivo. Essa técnica é desenvolvida para auxiliar os pacientes a experimentarem as situações temidas imaginando que elas estão ocorrendo naquele exato momento. No consultório ou como tarefa entre as sessões, os pacientes são solicitados a "vivenciar" na imaginação a situação temida e a construir as melhores estratégias de enfrentamento para superá-la com sucesso futuramente (KNAPP, BECK, 2008). O paciente, obtendo recursos para persistir, pode-se lançar na busca de outras hipóteses para atingir a meta. Ana pode fazer natação, um exercício de baixo impacto para quem tem problemas nas articulações, entre demais alternativas.

$\mathrm{Na}$ análise do caso em questão, e de maneira gradativa, parte-se então de uma hipótese factual categórica, e chega-se a versões mais flexíveis dessa hipótese. Ou seja, há um enfraquecimento da hipótese, o que conflui com a flexibilização e a modificação de crenças no esquema cognitivo. Em outras palavras, a modulação de metas proativas junto ao paciente pode se configurar uma estratégia descritiva, especialmente para o teste de realidade, quando o paciente de fato executa a ação antecedente $P$; e a análise das conciliações da meta e das confirmações hipóteses pode contribuir para a compreensão do processo de fortalecimento ou enfraquecimento de suposições que compõem o conjunto de crenças do paciente.

\section{CONSIDERAÇÕES FINAIS}

O modelo cognitivo da TC trabalha com a hipótese de que as emoções e os comportamentos são influenciados pela percepção dos eventos. Desse modo, não é a situação por si só que determina o que as pessoas sentem, mas antes, o modo como elas interpretam a situação. Existe uma estrutura interna que filtra, codifica e avalia essas situações com base em uma matriz de esquemas. Intervenções que aumentem o senso de autoeficácia do paciente podem favorecer a diminuição da intensidade de sua sintomatologia e facilitar outras intervenções. Estas intervenções devem visar à modificação dessa estrutura mais profunda - as crenças. 
A utilização de técnicas cognitivas consiste em uma forma de ampliar o ambiente cognitivo por um processo de construção de hipóteses abdutivas, tanto ao trazer uma suposição nova como ao reapresentar uma mesma suposição combinando com novas evidências. Isso permite não somente questionar os pensamentos disfuncionais, mas as crenças que os fundamentam. As técnicas serão relevantes, na medida em que elas forem formuladas em um ambiente cognitivo mútuo entre terapeuta e paciente e, consequentemente, apresentarem algum efeito contextual, levando à alteração dos pensamentos automáticos e, por decorrência, à alteração das crenças do indivíduo.

Retomando a proposta de Rauen (2013), as crenças constituem esse nível mais categórico de hipóteses, ou seja, são experiências, valores, princípios tomados como absolutamente verdadeiros e globais. Nos termos de Rauen, trata-se de conexões certas, necessárias e suficientes: "Certamente e absolutamente Se P, então Q". Ao serem questionadas, essas crenças são sucessivamente enfraquecidas até o ponto de serem admitidas como tautológicas e, em extremo, irrelevantes: "Se $P$, então possivelmente $Q$."

Em síntese, é razoável supor que a modelação abdutivo/dedutiva de metas proativas, conforme os quatro estágios propostos por Rauen (2013), aliada aos conceitos de conciliação de metas e de confirmação de hipóteses, pode contribuir para a compreensão de como ocorre o processo cognitivo da flexibilização e de modificação de crenças disfuncionais, abrindo espaços para linhas de pesquisa promissoras na Terapia Cognitiva

\section{NOTAS}

\footnotetext{
${ }^{1}$ A autora é imensamente grata ao grupo de estudos em Teoria da Relevância da UNISUL, em especial pela inspiração dessas ideias.

${ }^{2}$ Mestre em Educação Agrícola pela Universidade Federal Rural do Rio de Janeiro (UFRRJ). Doutoranda do Programa de Pós-Graduação em Ciências da Linguagem Universidade do Sul de Santa Catarina (UNISUL). Psicóloga do Instituto Federal Catarinense (IFC/Campus Sombrio). E-mail: andreiabez@yahoo.com.br.
} 


\title{
MODIFICATION OF BELIEFS AND PROACTIVE MODELING OF GOALS: PERSPECTIVES OF INTERFACE
}

\begin{abstract}
In this paper, I evaluate the descriptive and explanatory potential of Rauen's (2013) Goal Conciliation Theory in Cognitive Therapy interventions. I argue that the success of the intervention consists in collaboratively designing goals, and the therapy consists in developing ante-factual abductive hypotheses, whose execution, as it generates conciliated results with designed goals, can weakening or making flexible the categorical connection of cause and effect in dysfunctional beliefs.
\end{abstract}

Keywords: Goal Conciliation Theory. Cognitive Therapy. Proactive Modeling of Goals. Ante-factual Abductive Hypotheses. Dysfunctional Beliefs.

\section{REFERÊNCIAS}

BECK, J. S. Terapia cognitiva: teoria e prática. Porto Alegre: Artes médicas, 1997.

DATTILIO, F. M. Reestruturação de Esquemas Familiares. Rev. Bras. Ter. Cogn. [online], v. 2, n. 1, p. 17-34, 2006.

KNAPP, P.; BECK, A. T. Fundamentos, modelos conceituais, aplicações e pesquisa da terapia cognitiva. Rev. Bras. Psiquiatr., São Paulo, v. 30, supl. 2, oct. 2008. Disponível em: <http://www.scielo.br/scielo.php?script=sci_arttext\&pid=S1516$44462008000600002 \&$ Ing=en\&nrm=iso >. Acesso em: set. 2013. http://dx.doi.org/10.1590/S1516-44462008000600002.

LEAHY, R. L. Como lidar com as preocupações: setes passos para impedir que elas paralisem você. Trad. Luzia Araújo. Porto Alegre: Artmed, 2007.

LINDSAY, R.; GORAYSKA, B. Relevance, goal management and cognitive technology. In: GORAYSKA, Barbara; MEY, Jacob. Cognition and technology: coexistence, convergence, and co-evolution. Amsterdam: J. Benjamins, 2004.

NEUFELD, C. B.; CAVENAGE, C. C. Conceitualização cognitiva de caso: uma proposta de sistematização a partir da prática clínica e da formação de terapeutas cognitivo-comportamentais. Rev. Bras. Ter. Cogn., Rio de Janeiro, v. 6, n. 2, dez. 2010. Disponível em: <http://pepsic.bvsalud.org/scielo.php?script=sci _arttext\&pid=S1808-56872010000200002\&lng=pt\&nrm=iso $>$. Acesso em: set. 2013. 
NEZU, A. M.; NEZU, C. M. Treinamento em solução de problemas. In: CABALLO, V. E. (Org). Manual de técnicas de terapia e modificação de comportamento. Trad. Marta Donila Claudino. São Paulo: Santos, 2002.

RANGÉ, B. Por que sou terapeuta cognitivo comportamental. In: BANACO, R. A. Sobre comportamento e cognição: aspectos teóricos, metodológicos e de formação em análise do comportamento e terapia cognitivista. Santo André: ESETec, 2001.

RAUEN, F. J. Hipóteses abdutivas antefactuais e a modelação proativa de metas. Signo, Santa Cruz do Sul, v. 38, n. 65, p. 188-204, jul./dez. 2013. Disponível em: <http://online.unisc.br/seer/index.php/signo>. Acesso em: 18 mar. 2014.

SPERBER, D; WILSON, D. Relevância: comunicação e cognição. Trad. de Helen Santos Alves. Lisboa: Calouste Gulbenkian, 2001.

WAINER, R. et al. Teorias linguísticas pragmáticas e a interpretação em psicoterapia cognitivo-comportamental. Revista Brasileira de Terapia Comportamental e Cognitiva, v. 7, n. 1, p. 39-54, 2005. 